\title{
Spatial Behaviour Modelling of Unauthorised Housing in Colombo, Sri Lanka
}

\author{
*GPTS HEMAKUMARA ${ }^{1,2}$ \\ RUSLAN RAINIS ${ }^{1}$ \\ ${ }^{1}$ Geography Section, School of Humanities, Universiti Sains Malaysia, \\ 11800 USM Pulau Pinang, Malaysia \\ Current affiliation: \\ ${ }^{2}$ Department of Geography, Faculty of Humanities and Social Sciences, \\ University of Ruhuna, Matara 81000, Sri Lanka \\ *Corresponding author: sam@geo.ruh.ac.lk
}

Published online: 26 September 2018

To cite this article: Hemakumara, GPTS. and Rainis, R. 2018. Spatial behaviour modelling of unauthorised housing in Colombo, Sri Lanka. KEMANUSIAAN the Asian Journal of Humanities 25(2): 91-107, https://doi.org/10.21315/kajh2018.25.2.5

To link to this article: https://doi.org/10.21315/kajh2018.25.2.5

\begin{abstract}
The rapid emergence of houses in the low-lying areas of developing countries, especially in South Asia, has led to increasing negative environmental effects in these regions. Therefore, here, an attempt is made to build a geo-spatial model that can be used as a guide and index to help understand how the unending emergence of individual households generally occurs. This study was conducted in the Colombo Metropolitan Region, in which the mass conversion of low-lying areas has already taken place to a great extent. The study was based on variables related to the behaviour of householders who were living in lowlying areas without having the proper legal right to occupy or use those lands. A spatial logistic model was developed based on seven explanatory variables, and this was used in conjunction with GIS-linked display maps to measure how the householders' behaviour increased the level of conversion of low-lying lands. The sample size was 294 houses comprising 185 stable and 109 non-stable houses in the core study area, which formed a part of the Colombo Metropolitan Region. The results of this study show that out of the seven variables tested, five variables are highly significant, and the accuracy of the database is approximately $86.7 \%$. A predicted probability map of the converted and nonconverted houses in the year 2012 has been categorised as an index of conversion. The final output of this study can be used as a guide and index with which to monitor, manage and shape low-lying areas during the town planning, house upgrading and rehabilitation stages.
\end{abstract}

Keywords and phrases: geo-statistical model, housing, lowland conversion, spatial behaviour, suburban 


\section{Introduction}

Urbanisation is a modern development responsible for causing marked environmental changes in the 21 st century, as it drives more than one half of the world's population to crowd into urban areas that cover just $2 \%$ to $3 \%$ of the entire land surface of the earth (Braimoh and Onishi 2007; Seto and Kaufmann 2003). Burgeoning urbanisation has caused the world's urban population to increase from 200 million in 1900 to approximately 2.9 billion in 2000, and this number is estimated to increase to approximately 5 billion by 2030 (United Nations 2012). As a consequence, the impact of land use in the urban sprawl has created several environmental and health-related issues that have ramifications that can be felt from a local level to a global level (Hasse and Lathrop 2003). The rapid and poorly regulated urbanisation proceeding apace in developing countries is responsible for causing much damage to the environment. This, in turn, has resulted in the deterioration of living conditions and an increase in the incidence of serious health problems caused by the inadequate supply and poor quality of water, lack of sanitation, unsatisfactory water drainage, poor household and industrial waste management, and air pollution (United Nations Development Program 2009; Zakaria 2007). The excessive generation of household wastes combined with inadequate recycling capacity is another problem caused by the rapid increase in low-lying land conversion (Barr 2007; Oskamp et al. 1991).

An important factor influencing the conversion of low-lying lands in urban areas is land value; this is due to the high demand from investors who want to utilise these lands for commercial purposes. For this reason, it has become economically more advantageous for land owners to utilise or divert lands for commercial development rather than put them to agricultural use. However, this practice can lead to many environmental issues, as pointed out by several researchers (Yeh and Li 1998; Makunde 2016). People who live in marginal areas at the city periphery, in particular, have a strong tendency to convert low-lying areas into home plots with gardens due to the ingrained spatial behaviour of people. This is because spatial behaviour has a major and distinct territorial component to it.

Land is the basic element involved in all aspects relating to development in a city. However, a common issue pertaining to land use in urban areas is unauthorised construction and development that is not in conformity with city planning. Many inhabitants of cities are concerned only about social and economic rewards and do not care about environmental issues. Hence, these individuals constantly attempt to encroach on the sensitive lands at the edges of cities (Ducrot et al. 2004). Many of these low-lying areas have the potential to create environmental problems in the surrounding regions, especially through flooding. A classic example of this 
issue can be seen in the Colombo Metropolitan Region and its low-lying areas (Subasinghe, Estoque and Murayama 2016). People, especially those living in low-lying areas, have a spatial and, more specifically, a territorial imperative that drives them to convert the land they are occupying into a permanent home garden. Therefore, this study attempts to analyse how people living in low-lying areas set attempt to establish their homesteads in the plots they have captured.

\section{What is Behaviour?}

Human behaviour refers to the range of behaviours exhibited by humans and that is typically influenced by culture, attitudes, emotions, values, ethics, authority, persuasion, coercion and/or genetics (Golledge and Stimson 1997). The behavioural traits of people can fall within a wide range, with some behaviours being common, some unusual, some acceptable and some outside acceptable limits. Hence, in this sense, household behaviour refers to the collective way of thinking of households; this can vary, and it can be either positive or negative behaviour (Hoogvorst 2003; Syphard et al. 2012). Social behaviour is behaviour specifically directed at other people. The acceptability of behaviour is evaluated relative to societal norms and regulated by various means of social control (Fehr and Fischbacher 2004).

\section{Spatial Behaviour}

Golledge and Stimson (1997) explained spatial behaviour, which is treated as a sub-branch of human behaviour and is used in geography and urban studies. Most people live in cities that are complex in terms of their form, functions, structure and environment. This environment has the power to mould people's attitudes, values and beliefs. The things that people learn and the ideas they pick up during the course of urban living will naturally be reflected in the way they make use of land resources. This is true of individuals, households, firms, institutions and even the government (Ariyawansa 2008). The availability of comprehensive geographic information system (GIS) data and related information is very useful for analysing the trend of human spatial behaviour (Kwan 2000). In addition, negative behaviour patterns can have serious effects on household development, with alcohol abuse, drug use, heavy smoking, gambling, unlawful/illegal activities and general misconduct deemed as negative behaviour that will lead to the undermining and eventual collapse of all household development (Hoogvorst 2003; Pearson, Montgomery and Locke 2009). Hence, in this study, seven spatial behaviour variables are applied to the model building process, specifically, the materials used (MU); technical skills and adaptation (TSA); living time per week in house (LT); smoking, drinking and drug habits (SDD); permanent plants growing in a plot (PG); public participatory practice (PPP) and family savings (FS). 


\section{Research Objectives}

Leading land utilisation planners have emphasised that time, space and human interactions are the most important factors in the context of land use conversion. Evidence of human interactions can be seen in the form of development sites, factories, concrete highways, tarmac roads and individual structures, and especially housing constructions that are scattered over sensitive areas such as low-lands, filled-in marshes and paddy fields. Colombo and its outlying suburban zones are among the most congested lands due to the individual housing units established densely across its low-lying areas. As explained in this study, this is a process that has been going on for a period of time, involving the encroachment and capture of every low-lying land plot and its eventual conversion into a stable home garden due to the occupant's spatial behaviour. Although this conversion process starts at the micro level within individual housing plots, its collective strength can be very high and can eventually lead to urban chaos on several fronts (Samat et al. 2012). Hence, this study has mainly addressed the spatial behaviour of unauthorised settlers in the context of low land conversion, as elaborated in the research objectives below:

1. What types of household conditions are prevalent in low-lying areas?

2. What are the significant human interactions in respect to their spatial behaviour on land plots in the low-lying areas?

3. At what probability is the land being converted with respect to their spatial behaviour?

\section{Behaviour Model Building}

Dependent variable of model: After close observation of the study area, it can be seen that different conditions prevail in the various housing units in the low-lying areas of the Colombo Metropolitan Region. However, they have been categorised into two groups by pre-survey interviews as stable and non-stable (Shinn et al. 1998). As mentioned in the main literature of the study, stable houses possess greater potential for survival and conversion into home gardens than non-stable houses. Therefore, it is important to identify and measure the level of stability with respect to conversion to facilitate future decisions about suburban planning (Liu and Yang 2015). Information about dependent variables, such as whether households are stable or not, have been obtained directly from the core research area during a series of questionnaire interviews held in 2012. Several questions were asked in the pre-questionnaire interviews, which were conducted in several phases. In phase one, householders were interviewed about the housing situation 
between 2001 and 2005 based on behaviour information. The main question was whether the respondent's house was stable in 2005, to which the answer could be yes or no. If the answer was no, all non-stable houses were taken as the subjects of the main model to determine what happened in the year 2012 .

The following information provided by the government relating to the definition of stable house was used as the guideline in the pre-questionnaire survey when some householders were uncertain about the status of their house. The pre-questionnaire survey was used only to distinguish between and demarcate the stable houses and non-stable houses in the study area.

1. Structural materials

The Department of Census and Statistics of Sri Lanka (DCSSL) conducts a national population and housing survey every decade covering the entire country. They record information with respect to the structural materials used in the construction of the walls, roof and floor of every house they visited. Accordingly, each house is classified as a permanent or nonpermanent structure. Table 1 was prepared from information provided by DCSSL, and this can be used as a guide to distinguish between the stable and non-stable houses in the low-lying areas.

Table 1. Classification of permanent housing units in the low-lying areas

\begin{tabular}{llll}
\hline & Walls & Roof & Floor \\
\hline Type one & $\begin{array}{l}\text { Brick/cabook/cement } \\
\text { blocks/stone (3) }\end{array}$ & $\begin{array}{l}\text { Tile/asbestos/ } \\
\text { concrete (3) }\end{array}$ & $\begin{array}{l}\text { Cement/terrazzo/tile/ } \\
\text { granite (3) }\end{array}$ \\
Type two & $\begin{array}{l}\text { Pressed soil blocks mud } \\
\text { (2) }\end{array}$ & $\begin{array}{l}\text { Metal sheets, tar } \\
\text { sheets (2) }\end{array}$ & Wood, rough cement (2) \\
Type three & $\begin{array}{l}\text { Cadjan/palmyrah/straw/ } \\
\text { plank (1) }\end{array}$ & $\begin{array}{l}\text { Cadjan/palmyrah/ } \\
\text { straw (1) }\end{array}$ & Mud/wood/sand (1) \\
\hline
\end{tabular}

Source: Department of Census and Statistics of Sri Lanka

Note: The numbers in parentheses are the assigned value for the model

2. Infrastructure availability

The structural materials used in construction are not the only indicators used to determine the status of permanency of a household. In fact, the availability of infrastructure to an individual household has the greater potential to decide its status as stable or non-stable in the low-lying lands. On the other hand, only houses that have already been constructed from good materials will be able to incorporate many of the infrastructure facilities that will enable the household to become more stable. The following infrastructural amenities are some of the desirable ones that 
help transform a non-stable house into a stable house, as noted from the answers given:

- Electricity supply

- Pipe-borne water supply

- Accessibility (good roads)

- Sanitary facilities: Toilet

- Sanitary facilities: Bathing

- Fence marking the boundaries of the plot

The conversion of individual housing structures from non-stable to stable depends on these housing elements; however, this is not attained at their inception, as in the case of a properly planned and designed house construction project. A stable condition can only be achieved after incorporating at least some of the above elements into the household at different stages over a period of time. Non-stable houses without infrastructure facilities expect to build in all the housing elements necessary to become stable houses based mainly on their level of strength in behavioural aspects. However, as they are currently non-stable, these houses have less potentiality for conversion from low-land to home garden conditions than the houses that have more infrastructural facilities.

As explained in Table 2, the behaviour model consists of the following variables. As is evident from the definitions of the dependent variables, non-stable houses have less potential to convert low-lying areas than stable houses, and the independent variables will be tested based on each of the variables' definitions.

Table 2. Description of variables, labels and encodings for behaviour model

\begin{tabular}{|c|c|c|c|}
\hline Label & Description & $\begin{array}{l}\text { Variable } \\
\text { type }\end{array}$ & Definition of variable \\
\hline MU & $\begin{array}{l}\text { Quantity of materials } \\
\text { used for land and } \\
\text { housing conversion } \\
\text { (in cubic meters) }\end{array}$ & Continuous & $\begin{array}{l}\text { Non-stable householders have used smaller } \\
\text { quantity of materials for land filling than stable } \\
\text { householders }\end{array}$ \\
\hline TSA & $\begin{array}{l}\text { Incorporation of } \\
\text { technology, skills and } \\
\text { adaptation in house } \\
\text { construction }\end{array}$ & Categorical & $\begin{array}{l}\text { Non-stable householders have used simpler } \\
\text { technology and skills in their house } \\
\text { construction than stable householders }\end{array}$ \\
\hline LT & $\begin{array}{l}\text { Living time per week } \\
\text { in particular house }\end{array}$ & Continuous & $\begin{array}{l}\text { Non-stable householders spend fewer hours in } \\
\text { their houses per week than stable householders }\end{array}$ \\
\hline
\end{tabular}


Table 2. (continued)

\begin{tabular}{llll}
\hline Label & Description & $\begin{array}{l}\text { Variable } \\
\text { type }\end{array}$ & Definition of variable \\
\hline SDD & $\begin{array}{l}\text { Smoking, drinking } \\
\text { and drug habits of } \\
\text { inhabitants }\end{array}$ & Categorical & $\begin{array}{l}\text { Smoking, drinking and drug usage are very } \\
\text { much higher among non-stable householders } \\
\text { than stable householders }\end{array}$ \\
PG & $\begin{array}{l}\text { Permanent plants } \\
\text { growing in a plot, i.e., } \\
\text { trees }\end{array}$ & Continuous & $\begin{array}{l}\text { Non-stable householders have grown } \\
\text { fewer large plants in their plots than stable } \\
\text { householders }\end{array}$ \\
PPP & $\begin{array}{l}\text { Behaviour in respect } \\
\text { of participatory and } \\
\text { group activities }\end{array}$ & Categorical & $\begin{array}{l}\text { Non-stable householders are less involved in } \\
\text { participatory and group activities than stable } \\
\text { householders }\end{array}$ \\
FS & Family savings & Continuous & $\begin{array}{l}\text { Non-stable householders have much smaller } \\
\text { savings than stable householders }\end{array}$ \\
\hline
\end{tabular}

If $p$ is the probability that the dependent variable (Y) is 1 , then $p(1-p)$ is the odds or likelihood ratio; $B_{0}$ is the intercept, and $B_{1}, B_{2}, \ldots, B_{7}$ are the coefficients that measure the contribution of the independent factors MU, TSA, LT, SDD, PG, PPP and FS to the variations in Y. To interpret the meaning of Equation 1 appropriately, it is necessary to express the coefficients as a power of the natural $\log (e)$, which gives the value of the odds ratio (Hosmer Jr., Lemeshow and Sturdivant 2013). The multivariate logistic regression equation for this model can be written as indicated below:

$$
\begin{aligned}
Y & =\operatorname{Logit}(p)=\operatorname{In}[p /(1-p)] \\
& =B_{0}+B_{1} M U+B_{2} T S+B_{3} L T+B_{4} S D D+B_{5} P G+B_{6} P P P+B_{7} F S
\end{aligned}
$$

Based on the empirical data collected at the interview and their summarised results, the definitions of variables have been set as the essential elements of data interpretation for SPSS analysis. Accordingly, non-stable householders have used a smaller quantity of materials for land filling than stable householders, followed by other variables such as TSA, LT, PG, PPP and FS. However, SDD has a much greater variation than other variables because SDD habits are high in non-stable houses.

For the three categorical variables, the following three hypotheses have been formulated as required for SPSS logistic model data interpretation: 
1. A lower level of technical skills and adaptations are more prevalent in the case of non-stable houses than stable houses. Then, "lower technical skills and adaptation" is the reference variable (i.e., houses built in low-lying areas will be subject to greater threats with respect to their stability, but if inhabitants of those houses possess basic skills such as masonry, carpentry and technical trades, etc., those will be useful for modernising the houses and enhancing their stability, as shown in Figure 2).

2. Fewer public participatory practices are observed in non-stable houses than stable houses. Then, "less public participatory practice" is the reference variable (i.e., members of the families in stable houses have engaged in the activities of societies that have helped them make their houses in low-lying areas more stable compared to the non-stable houses whose occupants did not engage in public participatory activities).

3. Alcohol users and smokers are more common in non-stable houses than stable houses. Therefore, "yes" is the reference variable.

The model has been built by coupling the GIS database with logistic statistical analysis. Arc GIS 10.1 software was used with IBM SPSS version 22 to performed the analysis. Using SPSS, the probability value of each household has been calculated for the model. Finally, the model information table was linked with the GIS attribute table to determine the spatial distribution of houses with their probability values indicating their status as stable or non-stable houses.

\section{Field Evidence of Inhabitants' Behaviour}

The type of materials used for filling in the individual housing plots is a crucial parameter in the context of low-lying area conversion. It is dependent on individual behaviours and attitudes as well as the economic condition of individual families. The types of materials vary from solid waste to soil. Figure 1 shows some of the materials that are used for land filling in the study area.

Technical skills adaptation (TSA) and public participatory practice (PPP) are also suggested variables for the behaviour model because their impact on conversion is very high. This is frequently observed in the field, and Figure 2 clearly indicates how these practices are continuing on a daily basis in the study area. 


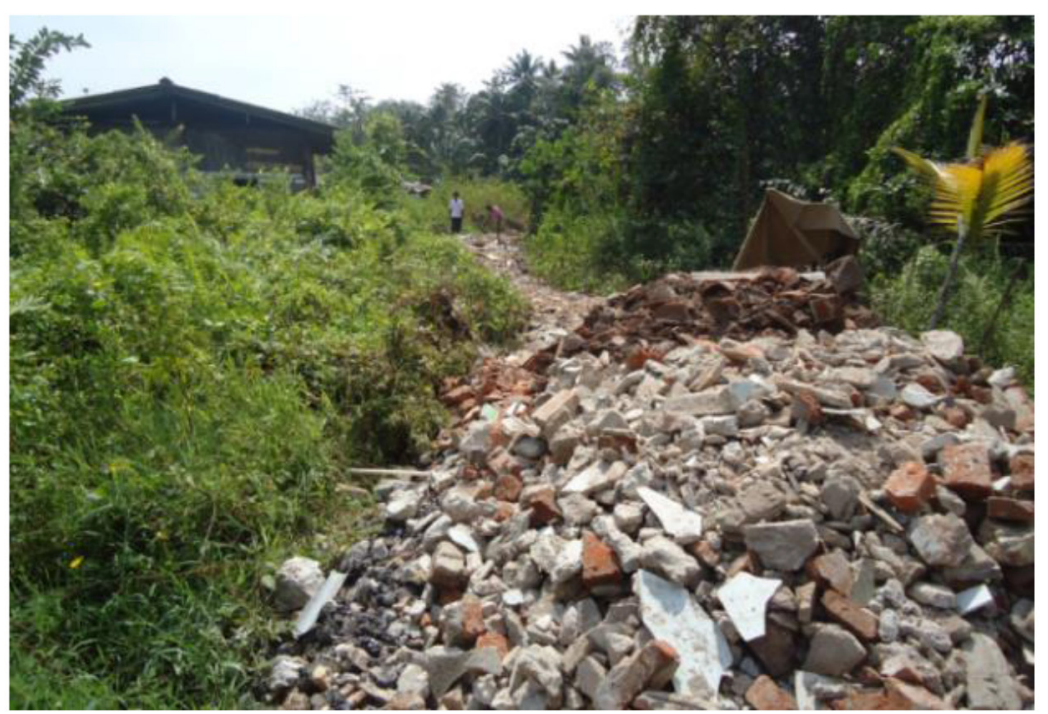

Figure 1. Households in the process of converting their land plots using easily available raw materials in the study area

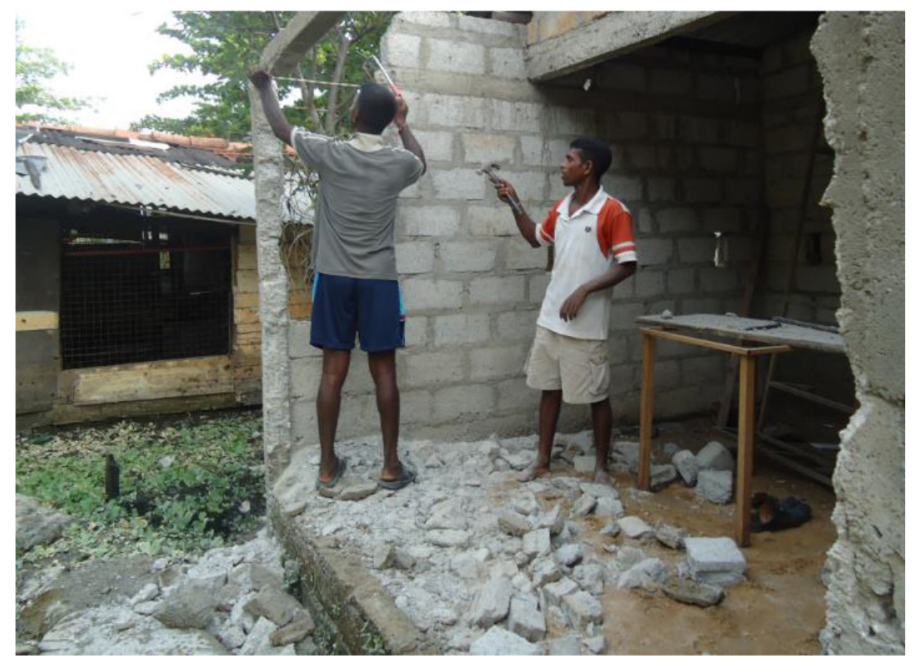

Figure 2. TSA and PPP activities in the study area 


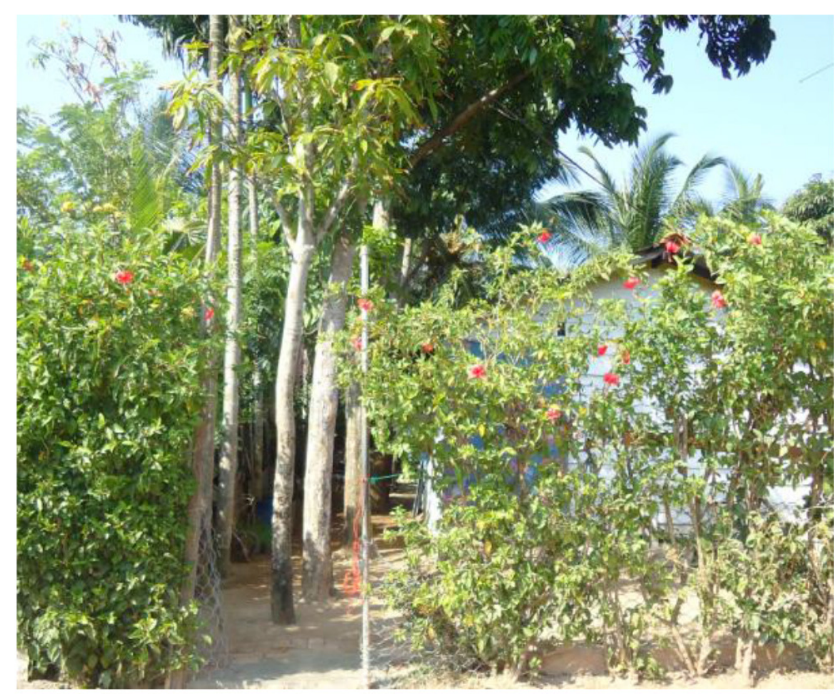

Figure 3. Growing permanent plants in the housing plots of the study area

Figure 3 shows how the strength of individual land plots in a low-lying area can be increased by growing some permanent plants (Jim 1993). Hence, this approach is commonly adopted by many householders in low-lying areas as a method of transforming their plots into stable households with home gardens.

As shown in Table 3, the model consists of seven explanatory variables that address the human behavioural aspects of low-lying land conversion. The dependent variable and its size are 294 households, none of which were found to be stable in the year 2005. However, at the time of the interview in 2012, when the housing type was chosen as the dependent variable of the model, the condition and status of many of the houses had changed so that there were only 109 non-stable houses, while the other 185 had developed into stable houses. This model can be expressed as a multivariate logistic regression equation, as in Equation 1.

Family savings (FS) has a -3 minimum value, which indicates that there are some families that do not have any savings at all, and at the end of each month these families have to obtain a micro loan from some external party to meet their monthly expense commitments. 
Table 3. Descriptive statistics of the model

\begin{tabular}{|c|c|c|c|c|c|}
\hline Labels & Units & Mean & Standard deviation & Min & Max \\
\hline MU & 100 cubic feet & 37.171 & 49.347 & 0 & 400 \\
\hline TSA & - & \multicolumn{4}{|c|}{ Variable with three categories } \\
\hline LT & Hours & 305.18 & 121.99 & 84 & 780 \\
\hline SDD & - & \multicolumn{4}{|c|}{ Dummy variable: Yes/No } \\
\hline PG & Trees & 4.14 & 4.214 & 0 & 22 \\
\hline PPP & - & \multicolumn{4}{|c|}{ Variable with three categories } \\
\hline FS & SL Rs. (000) & 3.285 & 4.857 & -3 & 29 \\
\hline
\end{tabular}

\section{Categorical Variable Settings for the Model}

In the model, there are three categorical variables out of the total seven variables relating to behaviour. TSA and PPP variables have been assigned with the categorical levels of low, moderate and high. Table 4 explains how the categorical variables have been set up according to the research argument.

Table 4. Categorical variable setting in the logistic model

\begin{tabular}{llccc}
\hline \multirow{2}{*}{ Variable } & \multirow{2}{*}{ Frequency } & \multicolumn{2}{c}{ Parameter coding } \\
\cline { 4 - 5 } TSA & & & $\mathbf{( 1 )}$ & $\mathbf{( 2 )}$ \\
& Low & 93 & 0.000 & 0.000 \\
& Moderate & 64 & 1.000 & 0.000 \\
\multirow{3}{*}{ PPP } & High & 137 & 0.000 & 1.000 \\
& Low & 94 & 0.000 & 0.000 \\
& Moderate & 92 & 1.000 & 0.000 \\
\multirow{3}{*}{ SDD } & High & 108 & 0.000 & 1.000 \\
& No & 184 & 1.000 & - \\
& Yes & 110 & 0.000 & - \\
\hline
\end{tabular}

In this model, there are seven variables, of which three are categorical and the other four are scalar. Hence, all three categorical variables have been assigned with their reference variables as the first rule, and the procedure of the logistic model is based on the hypotheses stated in the methodology section. 


\section{Model Accuracy}

The model correctly classified $86.7 \%$ of cases overall, which indicates how well it was able to predict the correct category (i.e., non-stable household vs. stable household) for each case in the behaviour model. Further details of the categorical division at the last step (Step 5) of the behaviour model are shown in Table 5. Out of the 109 non-stable houses observed, the model correctly identified $91(83.5 \%)$ of them as unlikely to score "1" in the predicted category. Similarly, out of the 185 stable households, the model correctly identified $164(88.6 \%)$ as likely to score " 1 " in the predicted category. Hence, out of the total 294 households, the model correctly identified and classified 255 households $(91+164)$, which indicates an accuracy of $86.7 \%$ for the cases tested.

Table 5. Classification of model accuracy

\begin{tabular}{|c|c|c|c|c|c|}
\hline \multirow{3}{*}{\multicolumn{2}{|c|}{ Observed }} & & \multicolumn{3}{|c|}{ Predicted } \\
\hline & & & \multicolumn{2}{|c|}{ Housing type } & \multirow{2}{*}{ Correct (\%) } \\
\hline & & & Non-stable (0) & Stable (1) & \\
\hline \multirow{2}{*}{ Step 5} & \multirow{2}{*}{ Housing type } & Non-stable $(0)$ & 91 & 18 & 83.5 \\
\hline & & Stable (1) & 21 & 164 & 88.6 \\
\hline \multicolumn{3}{|c|}{ Overall percentage } & & & 86.7 \\
\hline
\end{tabular}

Note: The numbers in bold indicate correct percentage of values

\section{Model Showing the Relationship between Household Status and Behaviour}

Table 6 indicates the regression coefficient (B), the Wald statistics (to test the statistical significance) and the odds ratio $[\operatorname{Exp}(B)]$ for each variable category. Looking at the results of the behaviour variable, the three highly significant variables are family savings (Wald $=19.553, p=0.000$ ), permanent plants growing in the plot (Wald $=18.989, p=0.000$ ) and technical skills (high category) (Wald $=18.849, p=0.000)$. These variables are significant as well as having a positive relation to a stable house. The $\operatorname{Exp}(\mathrm{B})$ (or odds ratio) at the $95 \% \mathrm{CI}$ indicates that a household with a good score in the high TSA category is 9.972 times more likely to make it into a stable house than one lacking these attributes. Overall, the behaviour model with its highly significant variables indicates stable households as having a positive relationship with five variables out of the total of seven. Therefore, a high probability value of each land plot in this model indicates high conversion strength in the context of behavioural factors. Conversely, a low probability value in this model indicates the inhabitants' incapability to make much progress in low-land areas due to deficiencies in certain aspects of human behaviour. 
Table 6. Model result as at iteration in Step 5

\begin{tabular}{lcccccc}
\hline & B & Std. error & Wald & df & Sig. & $\operatorname{Exp(B)}$ \\
\hline PPG & 0.383 & 0.088 & 18.989 & 1 & 0.000 & 1.467 \\
MU & 0.014 & 0.007 & 4.267 & 1 & 0.039 & 1.014 \\
PPP & & & 11.071 & 2 & 0.004 & \\
PPP(1) & 1.193 & 0.499 & 5.712 & 1 & 0.017 & 3.296 \\
PPP(2) & 1.548 & 0.493 & 9.875 & 1 & 0.002 & 4.701 \\
TSA & & & 18.871 & 2 & 0.000 & \\
TSA(1) & 1.171 & 0.500 & 5.497 & 1 & 0.019 & 3.226 \\
TSA(2) & 2.300 & 0.530 & 18.849 & 1 & 0.000 & 9.972 \\
FS & 0.408 & 0.092 & 19.553 & 1 & 0.000 & 1.504 \\
Constant & -3.861 & 0.568 & 46.228 & 1 & 0.000 & 0.021 \\
\hline
\end{tabular}

\section{Probability Value and Spatial Distribution}

According to Figure 4, a few stable houses also have lower probability values because the human behaviour variable values of some of their occupants are not favourable (Ayalew and Yamagishi 2005). However, in general, most stable houses have high levels of probability in terms of behavioural aspects. These high probability values indicate that stable houses that are strong in the human behaviour variables have been conducting the process of low-lying land conversion more effectively than the non-stable houses in the area. A few non-stable houses may also have reached up to probability level one, which indicates that even if their occupants live in non-stable houses, their behaviour variable levels are more comparable to those in stable houses during the process of conversion of their land plots. However, these houses still have not completely converted into stable houses because they may have failed in certain other parameters, such as socio-economic or environmental aspects. On the other hand, a high odds ratio indicates their high potentiality to become stable houses, as our research findings show. For example, the TSA of a high level has an odds ratio of 9.972 compared to the reference variable that has a low level of TSA. A high level of PPP also has a 4.701 odds ratio compared to a low level of PPP. The predicted probability values range between 0 and 1, but their locations and distribution cannot be placed accurately without GIS. 


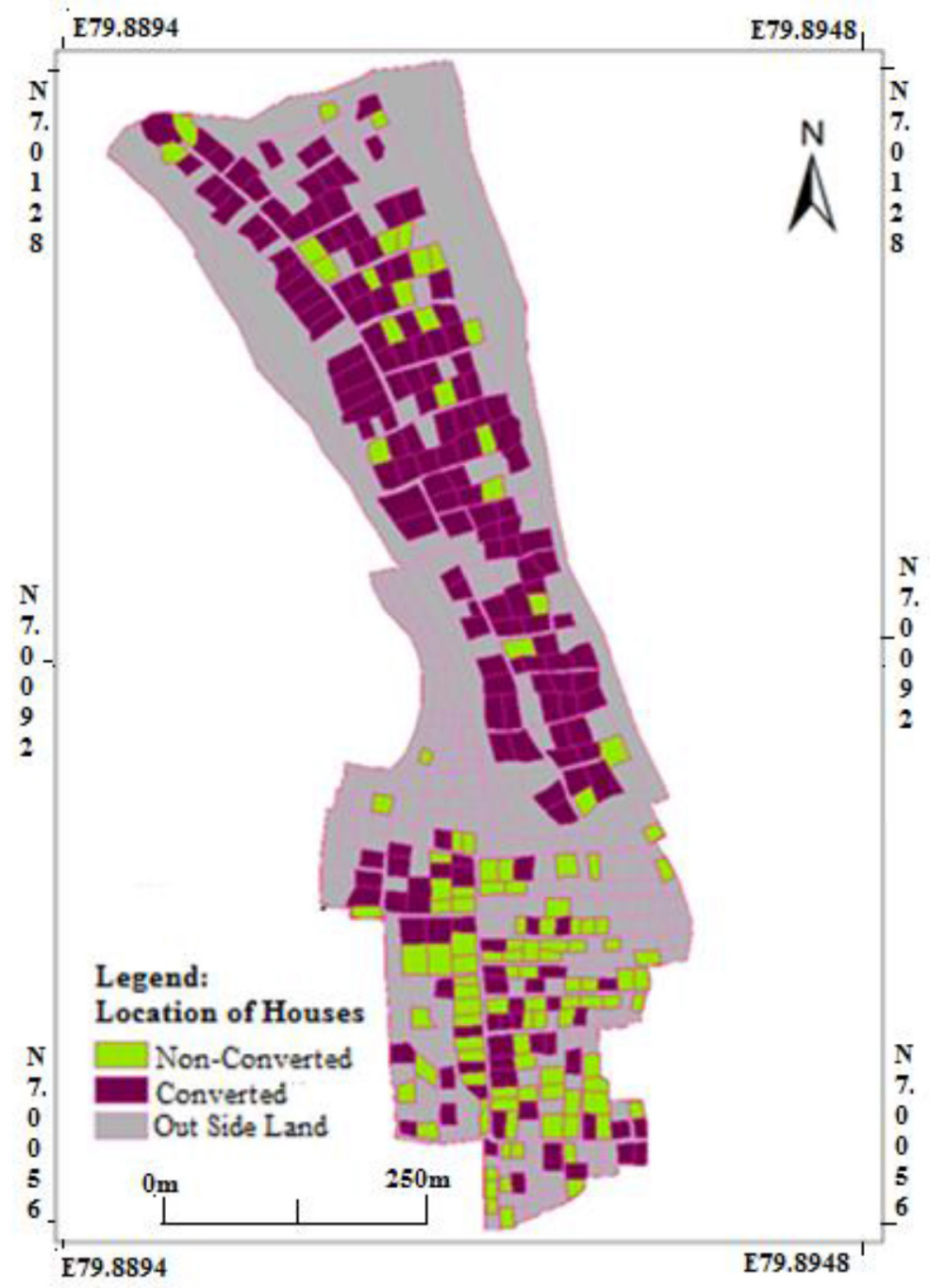

Figure 4. Spatial distribution of converted and non-converted houses

Figure 4 illustrates how the behaviour conversion values (predicted probability values) that were obtained by running the model are scattered over the study area. Figure 4 shows the non-stable houses that were present in 2005, but many of the same houses had changed into stable houses by the time the interview was held in 2012. Therefore, the non-stable houses that existed in the year 2005 were taken as the main database for the questionnaire interviews held in 2012. Deep magentacoloured land plots have probability values of greater than 0.5 and have been 
categorised as converted land due to their greater potentiality of conversion caused by certain aspects of human behaviour. On the other hand, green-coloured housing plots have probability values of 0.5 or less, and it is assumed they have not been converted because of this lower probability value.

\section{Conclusion}

The objective of this study was to measure the influence of factors that were responsible for the conversion of low-lying lands into housing plots. This study focused primarily on the effects of human intervention, which mainly depended on the behaviour of the persons who took possession of the lands by settling on them. According to the results presented by the model analysis, the behaviour model showed very good performance, as five variables out of the seven independent variables were significant. The three highly significant variables turned out to be family savings (Wald $=19.553, p=0.000$ ), permanent plants growing in the plot (Wald $=18.989, p=0.000)$ and technical skills (high category) (Wald $=18.849$, $p=0.000$ ). The variables bore a positive relationship to a stable house while also proving significant. A household that scored very well in the high TSA group was 9.972 times as likely to convert to a stable house than the one not meeting these conditions, as indicated by the $\operatorname{Exp}(\mathrm{B})$ or odds ratio of $95 \% \mathrm{Cl}$. Out of the seven highly significant variables of the behavioural model, five variables have a positive relationship with stable households. Hence, the most influential behaviour variables have been statistically and empirically proven to be important in the context of low-lying land conversion. Therefore, the model has effectively contributed towards identifying the most influential variables that have a direct impact on low-lying land conversion brought about by the emergence of households. The land plots of this model returned high probability values suggesting that the behavioural factors of the householders in the low-lying areas were responsible for the high conversion strength. In contrast to this, when the householders were unable to make much progress due to various shortcomings in their behavioural traits, the model indicated low probability values. Finally, the model's accuracy was measured at $86.7 \%$. In addition, the model's probability values have been linked to real locations on spatial maps using GIS techniques, and these can be used for resettlement programmes in these areas during urban planning stages. Based on the findings of this study, it is suggested that any local government or other planning body involved in the preservation of low-lying areas could use these results profitably in their work. They could apply this knowledge in their rehabilitation programmes for low-lying areas or for maintaining the sustainability of a region with better results. The values of the probabilities of the variables can be used as key indicators of the rehabilitation process. 


\section{Acknowledgements}

The authors wish to thank National Center for Advanced Studies in Humanities and Social Sciences (NCAS), Sri Lanka (grant number: 09/NCAS/RHU/Geo/35) for the research grant provided.

\section{References}

Ariyawansa, R. 2008. Property market in Colombo. Colombo: Self-published.

Ayalew, L. and Yamagishi, H. 2005. The application of GIS-based logistic regression for landslide susceptibility mapping in the Kakuda-Yahiko Mountains, Central Japan. Geomorphology 65(1): 15-31. https://doi.org/10.1016/j.geomorph.2004.06.010

Barr, S. 2007. Factors influencing environmental attitudes and behaviors. Environment and Behavior 39(4): 435-473. https://doi.org/10.1177/0013916505283421

Braimoh, A.K. and Onishi, T. 2007. Spatial determinants of urban land use change in Lagos, Nigeria. Land Use Policy 24(2): 502-515. https://doi.org/10.1016/j. landusepol.2006.09.001

Ducrot, R., Le Page, C., Bommel, P. and Kuper, M. 2004. Articulating land and water dynamics with urbanization: An attempt to model natural resources management at the urban edge. Computers, Environment and Urban Systems 28(1-2): 85-106. https://doi.org/10.1016/S0198-9715(02)00066-2

Fehr, E. and Fischbacher, U. 2004. Social norms and human cooperation. Trends in Cognitive Sciences 8(4): 185-190. https://doi.org/10.1016/j.tics.2004.02.007

Golledge, R.G. and Stimson, R.J. 1997. Spatial behavior: A geographic perspective. New York: The Guilford Press.

Hasse, J.E. and Lathrop, R.G. 2003. Land resource impact indicators of urban sprawl. Applied Geography 23: 159-175. https://doi.org/10.1016/j.apgeog.2003.08.002

Hoogvorst, A. 2003. Survival strategies of people in a Sri Lankan wetland: Livelihood, health and nature conservation in Muthurajawela. PhD dissertation, Wageningen University and Research, Netherlands.

Hosmer Jr., D.W., Lemeshow, S. and Sturdivant, R.X. 2013. Applied logistic regression (3rd ed.). Hoboken, NJ: John Wiley \& Sons. https://doi.org/10.1002/9781118548387

Jim, C.Y. 1993. Soil compaction as a constraint to tree growth in tropical and subtropical urban habitats. Environmental Conservation 20(1): 35-49. https://doi.org/10.1017/ S0376892900037206

Kwan, M.P. 2000. Analysis of human spatial behavior in a GIS environment: Recent developments and future prospects. Journal of Geographical Systems 2(1): 85-90. https://doi.org/10.1007/s101090050034

Liu, T. and Yang, X. 2015. Monitoring land changes in an urban area using satellite imagery, GIS and landscape metrics. Applied Geography 56: 42-54. https://doi. org/10.1016/j.apgeog.2014.10.002

Makunde, G. 2016. Challenges in urban development control and housing provision: A case of Epworth, Chitungwiza and Harare, Zimbabwe. International Journal of Technology and Management 1: 1-12. 
Oskamp, S., Harrington, M.J., Edwards, T.C., Sherwood, D.L., Okuda, S.M. and Swanson, D.C. 1991. Factors influencing household recycling behavior. Environment and Behavior 23(4): 494-519. https://doi.org/10.1177/0013916591234005

Pearson, C., Montgomery, A.E. and Locke, G. 2009. Housing stability among homeless individuals with serious mental illness participating in housing first programmes. Journal of Community Psychology 37(3): 404-417. https://doi.org/10.1002/ jcop. 20303

Samat, N., Elhadary, Y.A.E., Hijles, F.M., Suriati, G. and Morshidi, S. 2012. Poverty and deprivation: Using geographic information system in evaluating the accessibility of households to food retailers in Penang State, Malaysia. e-BANGI Jurnal Sains Sosial dan Kemanusiaan 7(2): 328-342.

Seto, K.C. and Kaufmann, R.K. 2003. Modeling the drivers of urban land use change in the Pearl River Delta, China: Integrating remote sensing with socioeconomic data. Land Economics 79(1): 106-121. https://doi.org/10.2307/3147108

Shinn, M., Weitzman, B.C., Stojanovic, D., Knickman, J.R., Jiménez, L., Duchon, L., James, S. and Krantz, D.H. 1998. Predictors of homelessness among families in New York City: From shelter request to housing stability. American Journal of Public Health 88(11): 1651-1657. https://doi.org/10.2105/AJPH.88.11.1651

Subasinghe, S., Estoque, R.C. and Murayama, Y. 2016. Spatiotemporal analysis of urban growth using GIS and remote sensing: A case study of the Colombo Metropolitan Area, Sri Lanka. ISPRS International Journal of Geo-Information 5(11): 197. https://doi.org/10.3390/ijgi5110197

Syphard, A.D., Keeley, J.E., Massada, A.B., Brennan, T.J. and Radeloff, V.C. 2012. Housing arrangement and location determine the likelihood of housing loss due to wildfire. PLoS One 7(3): e33954. https://doi.org/10.1371/journal.pone.0033954

United Nations. 2012. World urbanization prospects: The 2011 revision. New York: Department of Economic and Social Affairs (DESA), United Nations. http://www. un.org/en/development/desa/publications/worldurbanization-prospects-the-2011revision.html (accessed 24 March 2014).

United Nations Development Program (UNDP). 2009. UNDP annual report. New York: UNDP. http://www.undp.org/content/undp/en/home/librarypage/corporate/undp_ in_action_2009.html (accessed 22 April 2014).

Yeh, A.G. and Li, X. 1998. Sustainable land development model for rapid growth areas using GIS. International Journal of Geographical Information Science 12(2): 169189. https://doi.org/10.1080/136588198241941

Zakaria, R. 2007. Sustainable housing for residential-industrial neighbourhoods in Malaysia: A study on the elements of indoor environmental quality improvements. $\mathrm{PhD}$ dissertation, Queensland University of Technology, Australia. 